\title{
REPRESENTACIÓN SINDICAL EN ARGENTINA. UN CASO FUERA DE MODELO
}

\author{
David \\ Trajtemberg ${ }^{1}$ \\ Osvaldo \\ Battistini $^{2}$
}

\section{Resumen}

Las transformaciones económicas, políticas y culturales generadas por el neoliberalismo, en la última década del Siglo XX, en Argentina, produjeron un fuerte debilitamiento de las estructuras sindicales. Acosadas por el desempleo, la precarización laboral, las nuevas culturas del trabajo y el descrédito de gran parte de su dirigencia, muchas de esas organizaciones terminaron siendo funcionales al mismo modelo. Tras el abandono de las políticas neoliberales y el impulso otorgado por el gobierno de Néstor Kirchner, los sindicatos recuperaron gran parte de su fortaleza. Sin embargo, los cuestionamientos al modelo sindical emergieron con más peso que en otros momentos históricos. Los nuevos trabajadores, algunos de ellos contratados en los noventa, conformaron organizaciones que disputan la representación con los sindicatos tradicionales. Al mismo tiempo, sucesivos fallos de la Corte Suprema de Justicia de la Nación pusieron en jaque varios artículos de la Ley de Asociaciones Sindicales; los reclamos de OIT hablaron de la ausencia de libertad sindical, cuando dicha norma restringe la institucionalidad de nuevos sindicatos. En este artículo analizamos este momento sindical en Argentina, presentando los casos más relevantes que ponen en cuestión al régimen sindical, recurrimos a la comparación internacional y a la opinión de diversos especialistas en la temática.

Palabras clave: sindicatos, representación, representatividad, nuevos trabajadores, nuevas organizaciones.

\section{INTRODUCCIÓN}

\footnotetext{
${ }^{1}$ Economista (UBA). Postgrados en: UBA; UNTREF; y Centro de Formación OIT - Universidades de Bologna y Castilla La Mancha. Es Coordinador de Estudios en Relaciones Laborales en el Ministerio de Trabajo de Argentina y Docente de UNLAM. E-mail: dtrajtem@trabajo.gob.ar

2 Doctor en Sociología y Ciencias Sociales. Investigador Independiente CONICET. DocenteInvestigador Universidad Nacional de General Sarmiento (UNGS). Profesor en posgrado Universidad de Buenos Aires. E-mail: obattistini@gmail.com 
En los últimos años, el "modelo sindical” argentino está sufriendo fuertes críticas desde distintos sectores sindicales, políticos, jurídicos y académicos. Las transformaciones del trabajo (a partir de los cambios en la organización productiva y en las formas de gestión de la mano de obra), fundamentalmente producidas a partir de los años '9o, impulsaron la emergencia de nuevos trabajadores (muchos de ellos más jóvenes que los que hasta entonces conformaban el plantel de gran parte de las empresas, tanto públicas como privadas). Esta nueva realidad se tradujo también en nuevas culturas laborales. Culturas que, disciplinamiento empresario de por medio, en principio resistieron a las organizaciones sindicales y hasta, en algunos casos, desconocieron su presencia en los lugares de trabajo. Sin embargo, tras los acontecimientos de fines de 2001 y, con posterioridad, a partir de la recuperación de la economía y el consiguiente incremento del empleo, en el seno de estos nuevos colectivos laborales surgieron espacios de organización y lucha totalmente novedosos, muchos de los cuales contradijeron la lógica tradicional de la representación sindical. De esta forma, al conflicto capital-trabajo se adicionaría ahora un nuevo entramado de conflictos, generados al interior de las representaciones sindicales, entre estas nuevas formas representativas y las organizaciones tradicionales, las cuales comenzaron a defender lo que consideraban como espacio propio de representación.

Si bien, como observaremos en este artículo, en algunas actividades son varios los sindicatos existentes, no todos pueden acceder a la representación plena de los intereses de los trabajadores, lo cual sucede fundamentalmente con las organizaciones que se oponen a la lógica tradicional de la representación. La ley vigente y las diferentes estrategias de los distintos gobiernos combinan mecanismos que facilitan el funcionamiento pleno de algunos sindicatos y, al mismo tiempo, dificultan el de otros.

En el presente artículo analizaremos el proceso que acabamos de describir, para lo cual, en primer lugar detallaremos las características de la legislación vigente y su influencia en la determinación de la representación sindical. En segundo lugar, recorreremos algunas de las principales situaciones que dieron lugar a los cuestionamientos a dicha legislación, desde el surgimiento de nuevas organizaciones, los pronunciamientos de la OIT y los fallos de la Corte Suprema de Justicia de la Nación (CSJN). En tercer lugar, relevaremos las principales características de la representación 
sindical en algunos países latinoamericanos y europeos, con el fin de observar las diferencias entre ellos y respecto al modelo argentino, así como para poder dar cuenta de la inexistencia de uniformidades y funcionalidades sin contradicciones que puedan ser presentadas como ejemplo para nuestro país. Finalmente, recorreremos algunas perspectivas que analizan el modelo vigente y nos permiten pensar cuales son los problemas que tiñen la realidad gremial argentina así como sobre las posibles alternativas de reforma.

\section{EL MODELO DE LA LEY}

De acuerdo a la estricta lógica institucional del modelo sindical argentino, una sola organización debe primar en cada ámbito de representación. La legislación vigente no impide la existencia de más de un sindicato por espacio a representar, ya que habilita la inscripción de toda organización que demuestre contar con trabajadores afiliados, pero, al mismo tiempo dispone que sólo será otorgada la capacidad plena de representación a la que cuente con el mayor número de afiliados. De cualquier modo, la determinación de esta cantidad no resulta absolutamente clara, ya que no existen parámetros de real objetividad que puedan zanjar las disputas entre organizaciones que dicen representar el mismo espectro laboral. Al mismo tiempo, la representación institucionalizada no determina la representación concreta que se ejerce en el lugar de trabajo y, con el correr del tiempo, la distancia entre una y otra se ha hecho cada vez más grande, con lo cual se podría poner en duda aún si es válido centrar la idea de representatividad solamente en parámetros cuantitativos y, menos aún, cuando dichos parámetros, en base a los cuales se puede establecer alguna posible cuantificación, son manejados por las organizaciones que ya cuentan con representación formal e institucionalizada.

De todos modos, el sistema por el cual se determina la representación sindical data de mediados de los años 40, mientras que el origen del sindicalismo argentino se remonta a fines del siglo XIX. Las primeras organizaciones obreras derivaron del impulso de las ideas anarquistas, socialistas, comunistas y, más adelante, sindicalistas revolucionarias. Con el tiempo, cuando cada corriente ideológica conformó su propia confederación, los diferentes espacios de poder, en torno a la representación de los 
trabajadores, se disputaron de acuerdo a la forma en que cada una de ellas consideraba a la acción gremial.

Tres ejes principales distanciaban dichas posiciones: las relaciones con el Estado y los partidos políticos (autonomía o dependencia); las formas de encarar la lucha (acción directa o negociación); las estrategias de organización (estructura permanente y estable u organización según la coyuntura). Diferencias que, en principio, hacían impensable la idea de la convergencia en una sola central. Con matices, algunas de estas contradicciones (sobre todo las dos primeras) permean aún parte de los debates sobre el sindicalismo e incluso distancian posiciones entre las centrales existentes.

La creación, en 1930 de la Confederación General del Trabajo (CGT) comienza a centrar parte de esas disputas al interior de una sola Central y posterga otras discusiones $^{3}$. La nueva Central inaugura un proceso de estabilidad organizacional del sindicalismo. Las necesidades derivadas del crecimiento del empleo industrial, que generaba una relativa estabilización de los trabajadores en sus puestos de trabajo y, con ello, la concentración de sus intereses en lo que sucedía en su entorno más cercano (el lugar de trabajo), producían cierta resistencia de dichos trabajadores a las consignas de mayor que, además, los obligaban a la movilización permanente. Un reflejo de esta nueva situación fue la estabilización de la estructura sindical y, con ella, el arribo de sindicalistas que pasaron a actuar como miembros permanentes de las organizaciones

\footnotetext{
${ }^{3}$ La creación de la CGT no significó el fin de las divisiones al interior del movimiento obrero. Los primeros años diferentes confederaciones representaron las distintas corrientes ideológicas en pugna. A mediados de los años cuarenta, cuando Perón llega al poder, la CGT estaba dividida en dos: CGT 1 (ligada a la postura sindical de separar la acción obrera de la política) y CGT 2 (resultado de una alianza entre socialistas y comunistas) (Godio, 1990: 31). Finalmente Perón fuerza la unificación, pero bajo una conducción ideológica y políticamente cercana, que se sostiene más allá de su mandato. Durante los años sesenta, bajo el impulso del influjo ideológico del marxismo revolucionario, a partir del ejemplo de la revolución cubana y con el objetivo de enfrentar a la denominada como "burocracia sindical", diversas organizaciones disputaron espacios frente a la CGT y sus sindicatos adheridos. Esto generó la conformación de una central sindical alternativa, donde convivieron dirigentes marxistas y peronistas de izquierda, la "CGT de los Argentinos", jamás reconocida por el Estado, pero con un papel político muy trascendente en la generación de reivindicaciones obreras y en el desarrollo de formas de acción directa, como el "Cordobazo", en mayo de 1969, y otros movimientos posteriores con las mismas características (James, 1999: 292-311). La existencia de esta central fue efímera, ya que la represión de la dictadura militar y el aislamiento a que la somete la CGT termina con su disolución en 1970. Otras divisiones iban a sucederse en el tiempo, como la que se desarrolla durante la dictadura militar, de 1976 a 1983, entre "conciliadores" con el gobierno (CGT Azopardo) y "confrontacionistas", división que perduro hasta entrado el retorno de la democracia, bajo el gobierno de Alfonsín (Fernández, 1998). En 1984 se logra la reunificación de la central obrera, que volverá a fraccionarse durante el siguiente gobierno democrático.
} 
obreras. Iban a ser estos últimos quienes, reemplazando al colectivo obrero, lo representaran como interlocutores ante los patrones y el Estado. A partir de entonces, sin negar el conflicto, la negociación pasaba a ocupar un lugar importante en la acción sindical, para lo cual estaban capacitados los nuevos representantes. La acción directa comenzaba a espaciarse y articularse con momentos de negociación, constituyendo alternativas que se utilizarían según las premisas que indicara cada coyuntura. Por otra parte, las presiones del Estado y de los empresarios también propiciaban estas condiciones, ya que una negociación entre interlocutores estables permitiría mayor previsibilidad en el mediano y largo plazo. Fueron entonces, los dirigentes sindicales los que, desde entonces, se encargaron de articular la dupla conflicto-negociación, según lo requirieran las necesidades económicas, sociales o políticas de cada momento. De esta forma, se produjo cierta profesionalización de los cuadros sindicales y, con el tiempo, una nueva actividad rentada para los trabajadores, la cual iba a requerir otro tipo de preparación y una relación distinta con sus propios compañeros (Del Campo, 1983). Este mismo proceso derivó también en la opción casi generalizada por estructuras que respondían a la lógica de la rama o actividad, abandonando paulatinamente el oficio como eje identitario para la conformación gremial.

Los derechos otorgados, a partir de su primer gobierno (1946-1952), por Juan D. Perón a los trabajadores y la consiguiente ampliación de su ciudadanía social se complementarían con el acceso directo y privilegiado de la clase obrera al Estado, por intermedio de los sindicatos (James, 1999: 32). De cualquier modo, esto era también el resultado de una transacción entre las organizaciones obreras y el gobierno, ya que si éste último iba a garantizarles su existencia y validación institucional, ellas se constituirían en el reaseguro del control concreto sobre la movilización de los trabajadores.

La institucionalización de los sindicatos se concretó mediante el Decreto-Ley 23.852, de 1945 (Etala, 2010). Desde allí en adelante, la unicidad sindical pasó a ser una de las características básicas del gremialismo argentino, conformándose en la moneda de cambio que legitimaba la transacción que describimos. La "personería gremial" constituyó el filtro principal para dotar o no de poder pleno a las organizaciones gremiales y, desde allí, para limitar discrecionalmente al pluralismo sindical. 
Hasta 1988 fueron varias los ensayos de reforma legal que, siguiendo los vaivenes de los gobiernos democráticos o dictatoriales y con mayor o menor éxito, marcaron la existencia del modelo sindical. Tras el fallido intento de reforma, a comienzos del gobierno de la Unión Cívica Radical, en 1983, el Parlamento aprueba, en 1988, la Ley № 23.551, denominada Ley de Asociaciones Sindicales (LAS). ${ }^{4}$

De todos modos, tal como veremos más adelante, cuando lo imponía la búsqueda de mayor gobernabilidad, tanto el Estado nacional como los Estados provinciales habilitaron mecanismos que contornearon lo establecido en las leyes para impulsar formas sindicales que no se ajustaban a ellas. Por el contrario, cuando la demanda de organización era disfuncional a dichas necesidades, la misma Ley se constituyó en un cerrojo insalvable y, como tal, reaseguro de la unicidad sindical. De esta manera, los sucesivos gobiernos lograron disciplinar a los sindicatos "amigos", separarlos de aquellos que no podían ser controlados y, de esa forma, neutralizar el frente sindical.

La Ley 23.551 reafirmó los lineamientos principales establecidos desde 1945, instituyendo que es el sindicato más representativo, en tanto logre afiliar a la mayor cantidad de trabajadores del ámbito que desea representar, el único que puede obtener la "personería gremial” y, así ser el único que puede ejercer la plena representación en dicho ámbito 5 . Como dijimos, esto no cercena la posibilidad de que otros sindicatos puedan existir en el mismo espacio, ya que la figura de la "personería jurídica" (o simple inscripción) así lo determina, que es el paso previo a la obtención de la "personería jurídica”. Si la simple inscripción no requiere más que un trámite administrativo de demostración de la existencia de la organización, las dilaciones en que el Estado incurre para otorgarla, en algunos casos, se constituyen en la primera dificultad a sortear. Pero, la barrera más importante aparece una vez dado este paso, ya que las restricciones para alcanzar la representación plena ${ }^{6}$ son, para determinadas organizaciones, prácticamente

\footnotetext{
${ }^{4}$ Para mayor precisión sobre este proceso ver: Etala, 1995; Battistini, 2011; Topet, 2009.

${ }^{5}$ Según art. 11 de dicha ley, las asociaciones sindicales pueden organizarse en tres niveles: en la rama, como sindicatos o uniones; en la actividad, como federaciones (dentro de las cuales se ubicarían los sindicatos o uniones); y en el de las confederaciones, cuando agrupen a las uniones y federaciones.

${ }^{6}$ Hablamos de representación plena cuando los sindicatos alcanzan la "personería gremial" ya que son los únicos que pueden representar a los trabajadores tanto en el conflicto como en la negociación, así como en la defensa de los intereses individuales de los mismos. Dichas organizaciones cuentan, además, con la posibilidad de determinar, en tiempo y forma, las elecciones vol.08, nº. 01, Rio de Janeiro, 2015. pp. 386-419 391
} 
insuperables. Si dos o más sindicatos cuentan con simple inscripción en un determinado ámbito, se produce lo que se denomina como "disputa de encuadramiento", ante lo cual el Estado terminará otorgando la representación plena, mediante la "personería gremial", a la organización que demuestre contar con el mayor número de afiliados en el ámbito que corresponda. La organización que pierda esta disputa puede seguir funcionando como tal, pero sus derechos de representación quedarán muy acotados y sus recursos jurídicos y económicos de actuación serán severamente limitados. Entonces, si el reconocimiento jurídico de la existencia de una organización gremial (simple inscripción) otorga la posibilidad de representar a los trabajadores a cualquier organización que lo solicite, la segunda exigencia (de obtención de personería gremial) la niega o, por lo menos, le establece limitaciones insalvables. Un sindicato que solamente cuente con simple inscripción puede ejercer la representación colectiva de los trabajadores del ámbito que pretende representar mientras en el mismo no exista otro sindicato que cuente con personería gremial (art. 23, inc. b). La cobertura extendida de organizaciones con personería gremial impide a otras organizaciones disputarla con posibilidades de éxito. Es la misma ley la que, en principio, clausura dicha posibilidad, ya que en su art. 28 especificó que: en caso de existir "una asociación sindical de trabajadores con personería gremial, solo podrá concederse igual personería a otra asociación, para actuar en la misma zona y actividad o categoría, en tanto que la cantidad de afiliados cotizantes de la peticionante, durante un período mínimo y continuado de seis meses anteriores a su presentación, fuere considerablemente superior a la de la asociación con personería preexistente”. El Decreto № 467/88, reglamentario de la LAS, en su artículo 21, precisa la indeterminación del criterio de superioridad de la ley estableciendo que "Cuando dos asociaciones tuviesen igual zona de actuación, la asociación que pretenda la personería gremial deberá superar a la que con anterioridad la posea como mínimo en el diez por ciento (10\%) de sus afiliados cotizantes". Pero, la dificultad para acceder a datos certeros sobre la cantidad de afiliados que tienen los sindicatos y la consiguiente magnificación que realizan los mismos sobre dichos datos, directamente impiden conocer cual sería el número de afiliados que se debe superar. Al mismo tiempo, la

de delegados, y los representantes finalmente elegidos bajo dichas reglas son los únicos que, según la ley, estarán protegidos por la tutela sindical. 
estructura de la representación por rama conforma otro obstáculo para algunas organizaciones que pueden ser representativas en espacios más reducidos (empresa o zona geográfica). Si un sindicato tiene personería gremial en una rama y otra organización cuenta con un número de afiliados mayor al mismo en un espacio inferior a dicha rama, no podrá disputar la representación hasta que no obtenga la mayoría en toda la rama.

La misma práctica sindical corriente refuerza la capacidad de las organizaciones con personería gremial de reproducir y ampliar el espacio de representación que ya tienen delimitado. Al ser el único que puede entrar en conflicto y negociar con sus contrapartes (Estado o empresarios) el sindicato que tiene esta prerrogativa cuenta con recursos simbólicos y materiales que le son útiles para garantizar su legitimidad. Para un trabajador, el hecho que el representante cuente con todas las garantías para ejercer su defensa en todos los ámbitos en que sindicalmente pueda llevarla a cabo, le otorga mayores seguridades que las que pueda ofrecerle un representante no plenamente reconocido.

Pero, además, es la Ley № $14.250^{7}$ la que establece cual es el colectivo de trabajadores que será representado por un sindicato en los procesos de negociación con los empresarios. De acuerdo a esta Ley, la negociación colectiva adquiere en Argentina el carácter de erga omnes, ya que los derechos resultantes de las negociaciones colectivas homologadas, llevadas a cabo entre un sindicato y un empresario individual o una o más asociaciones empresarias, se harán extensivos a todos los trabajadores del ámbito de actividad referido en dicha negociación, sin necesidad de que los mismos estén afiliados al sindicato. De esta forma, el sindicato es relevado de la necesidad de validar permanentemente su representatividad frente a los trabajadores, ya que al contar con la personería gremial es el único que puede negociar, lo cual le traslada inmediatamente la representación del conjunto de trabajadores por los cuales negoció. De este modo, la representación de los trabajadores se ejerce de arriba hacia abajo. Son los sindicatos existentes y los empresarios con los cuales negocian los que determinan quienes serán los trabajadores finalmente representados. ${ }^{8}$

\footnotetext{
${ }^{7}$ Se trata de la ley sobre Convenios Colectivos de Trabajo y fue dictada en septiembre de 1953.

${ }^{8}$ Uno de los ejemplos más crudos de este esquema fueron ciertos CCT llevados a cabo a nivel de empresa durante los '9o. Los mismos fueron firmados entre las partes y homologados por el vol.08, $n^{\circ}$. 01, Rio de Janeiro, 2015. pp. 386-419 393
} 
Al mismo tiempo, si un sindicato, por tener la personería gremial, cuenta con la potestad de recaudar las cuotas de afiliación y la ventaja que el dinero correspondiente a las mismas sea retenido directamente de los salarios por el empleador ${ }^{9}$, un mecanismo impuesto en la negociación colectiva les permite obtener otras fuentes de financiamiento adicionales. El art. 9 de la Ley 14250 indica que la convención colectiva podrá contener cláusulas que establezcan contribuciones a favor de las asociaciones sindicales, que serán válidas no sólo para los afiliados sino también para los no afiliados comprendidos en dicha convención. Mediante este mecanismo varios sindicatos han negociado lo que se denomina como "cuotas solidarias", que obligan a los trabajadores no afiliados a pagar una cuota mensual al sindicato, lo cual configura una especie de "derecho de negociación", por el hecho de verse "beneficiados" por lo obtenido en los convenios sin adherir explícitamente a la organización sindical. ${ }^{10}$ El aporte mensual (también retenido del salario del trabajador por el empleador) es prácticamente del mismo monto que el que pagan los afiliados, lo cual reduce los incentivos para la afiliación $^{11}$. Pero además, varios sindicatos acuerdan el pago de contribuciones monetarias de carácter mensual por parte de los empresarios. Ambas cuotas, la de los trabajadores afiliados y la de los empresarios, se destinan, según indica alguno de los convenios colectivos al "cumplimiento y desarrollo de los fines culturales, gremiales y

Ministerio de Trabajo antes que las dichas empresas estuvieran totalmente instaladas y, por lo tanto, antes que los trabajadores fueran contratados. Es decir, en estos casos el sindicato se auto-adjudicó la representación de trabajadores aún inexistentes, como sucedió. Algunos de los CCT más significativos fueron los firmados entre Sindicato de Mecánicos y Afines de la Industria Automotriz (SMATA) con la empresa General Motors (CCT 98-1994-E), en 1994, y con Toyota, en 1996 (CCT 1901996-E). Por las características flexibles de su ordenamiento, el primero de estos convenios fue presentado por el presidente Carlos Menem, en la apertura de las sesiones ordinarias del Parlamento del año 1995, como el ejemplo paradigmático de cómo debían ser regidas, en adelante, las relaciones laborales modernas en las empresas.

${ }^{9}$ El sindicato que sólo tiene personería jurídica puede imponer cotizaciones a sus afiliados pero, según indica la ley, en este caso, el empleador no tiene obligación de retenerlas a favor del sindicato.

${ }^{10}$ Según los defensores de este tipo de cláusulas, el objetivo de las mismas es neutralizar el efecto de los free rider, "pasajeros clandestinos" que aprovechan los beneficios de la negociación sin siquiera ser parte del sindicato que los obtuvo. Si bien acuerda con que los trabajadores no afiliados deben realizar un aporte al sindicato por la firma del CCT, el dirigente de la Central de Trabajadores Argentinos (CTA), P. Wasiejko, indica que lo conveniente sería el establecimiento de un aporte único a la firma del convenio y no una cuota mensual compulsiva.

${ }^{11}$ De cualquier modo, la afiliación se sostiene aun en porcentajes relativamente elevados (según una encuesta realizada por el Ministerio de Trabajo de Argentina, en 2005 era del 37,2\%, en 2006 del $39,7 \%$ y en 2008 del $37,7 \%)$. 
otros". Estos montos de dinero son generalmente administrados por el consejo directivo de los sindicatos, aparte del dinero que ingresa por cuotas de afiliación.

Entonces, cada uno de estos dispositivos termina constituyendo una garantía de la "apropiación" y perdurabilidad de la representación en manos de algunos sindicatos y en desmedro de la posibilidad que otros ejerzan tal representación, aún cuando su grado de representatividad en las bases sea mayor.

\section{EL MODELO VIGENTE EN CONTRADICCIÓN}

\section{Una nueva representación para cada realidad}

A pesar de los cuestionamientos que, durante los años sesenta y setenta se generaron a la representación sindical y, fundamentalmente, a la estructura burocrática que de ella derivaba, es en la actualidad cuando las contradicciones respecto a la legislación y a otras fuentes institucionales para su constitución se vuelven más notorias.

Fue durante el desarrollo del neoliberalismo en Argentina cuando se generaron las condiciones que derivaron en la situación actual. Hasta entonces, el mercado de trabajo argentino mostraba bajos niveles de desempleo y de informalidad laboral. La aplicación a rajatabla de las pautas establecidas en el Consenso de Washington produjo cambios sustanciales en el trabajo. Las privatizaciones, la apertura indiscriminada del mercado y la aplicación de las medidas flexibilizadoras implicaron una drástica reducción del número de trabajadores ocupados y la precarización de gran parte de los empleos que fueron creados en esos tiempos. La fuerte legitimación otorgada por la crisis económica, que impulsó la salida anticipada del gobierno de Alfonsín y la asunción de Menem sirvió como marco para prefigurar una situación de consenso forzado a estas medidas y, de esa forma, diluir cualquier posible oposición a las mismas.

Sin embargo, el surgimiento de la CTA fue uno de los primeros síntomas de que algún descontento se estaba gestando en la sociedad. Entre 1991 y 1992, los sectores más progresistas del sindicalismo argentino, opuestos al rumbo que tomaba la política nacional y a la actitud concesiva de la cúpula de la CGT frente a las mismas, 
conformaron esta nueva Central, que recién en 1997 obtiene la personería jurídica. ${ }^{12}$ Diecisiete años después, habiéndose sucedido desde entonces cuatro gobiernos democráticos, aún no se le ha otorgado la personería gremial. Desde 2008, a los reclamos ante los sucesivos gobiernos realizados por la dirigencia de la Central, se sumaron las observaciones del Comisión de expertos en Aplicación de Convenios y Recomendaciones de la Organización Internacional del Trabajo (OIT) sobre el hecho que, desde 2004, se encuentra aún pendiente la resolución del pedido de personería gremial realizado por dicha Central.

Esta negativa estatal se contradice fuertemente con la actitud que cada uno de los gobiernos tuvo frente a los dirigentes de la CTA, ya que, desde 1997 en adelante, la misma fue convocada para formar parte de distintos mesas de negociación y foros de trascendencia nacional e internacional.

Tal como lo indica H. García (2009: 7), fueron las mismas transformaciones del trabajo las que indujeron gran parte de las contradicciones entre lo que expresa la representación sindical tradicional y lo que ocurre al interior de los espacios laborales ${ }^{13}$. La reorganización y flexibilización del empleo y del trabajo impulsaron importantes cambios en dicho ámbito que motivaron heterogeneidades (de actividades, de saberes productivos, de identidades, etc.). En los años noventa, el crecimiento de la tasa de desocupación facilitó a las empresas la selección y adaptación de los trabajadores a sus necesidades. Las firmas con mayores recursos económicos y administrativos dispusieron mecanismos especializados para el reclutamiento y gestión de la mano de obra, adaptando sus necesidades a cada coyuntura. La presión ejercida por el desempleo contribuyó a reducir las expectativas salariales de los trabajadores y habilitó a los

${ }^{12}$ Encabezados por la Asociación de Trabajadores del Estado (ATE) y la Confederación de Trabajadores de la Educación de la República Argentina (CTERA), un conjunto de líderes sindicales tuvieron su primer encuentro en la Ciudad de Burzaco (Provincia de Buenos Aires), el 17 de diciembre de 1991. El 14 de noviembre de 1992, los mismos dirigentes volvieron a reunirse en el Parque Sarmiento (Ciudad de Buenos Aires) y fundaron el Congreso de los Trabajadores Argentinos. Finalmente, el 4 y 5 de noviembre de 1996 , en el estadio Luna Park, durante el $7^{\circ}$ Congreso Nacional de Delegados se conforma lo que pasó a denominarse como Central de Trabajadores Argentinos. El año siguiente, el Estado, mediante la resolución 325-1997, le otorga la Inscripción Gremial.

${ }^{13}$ La misma CTA planteó, en sus orígenes, una forma alternativa de representación sindical, incorporando dentro de ella una concepción de trabajador que salía fuera de la definición estrecha que tradicionalmente tenían los sindicatos alistados en la CGT (empleado formalizado activo). Para la CTA son trabajadores los asalariados formales; los informales; los jubilados; los desocupados; los beneficiarios de prestaciones de la seguridad social; los autónomos y cuentapropistas (sin trabajadores bajo su dependencia); los asociados o autogestivos; y los de la actividad doméstica. vol.08, $n^{\circ}$. 01, Rio de Janeiro, 2015. pp. 386-419 
empleadores a generar profundas renovaciones en sus planteles. La flexibilización de las pautas contractuales y el debilitamiento del poder de las organizaciones sindicales abrieron las puertas para que decisiones de este tipo sean tomadas prácticamente sin que se produzcan importantes conflictos. La incorporación al mercado de trabajo de trabajadores muy jóvenes, con alto nivel de calificaciones formales, relativamente bajas expectativas salariales y con muy baja o nula cultura sindical o política creó incentivos para la apertura de un proceso de fuerte "juvenización" de la mano de obra. Condiciones que funcionaron, en primera instancia, para el disciplinamiento de los nuevos trabajadores y, con ello su adaptación a los valores propios de las empresas; en segundo lugar estos mecanismos permitieron aportar al fraccionamiento de los colectivos de trabajo y la consiguiente separación de los trabajadores respecto a sus posibles representantes sindicales.

A estas condiciones se sumaban además cambios tecnológicos y organizacionales que motivaban nuevas formas de trabajo y nuevas capacidades para el ejercicio de las actividades cotidianas en los puestos de trabajo, lo cual dio lugar por ejemplo a la existencia de trabajadores polivalentes, con conocimientos de computación y de idiomas, con facilidad para responder a los desafíos impuestos por el cambio permanente de las pautas de producción, etc. ${ }^{14}$

Al mismo tiempo, con las nuevas formas de organización del trabajo se incorporaron mecanismos destinados a reducir los costos empresarios y aumentar la productividad. Entre ellos, uno de los más destacados fue la tercerización o subcontratación. A partir de este dispositivo, las empresas lograron separar y aislar distintos grupos de trabajadores, distinguiendo a los que quedaban en el núcleo productivo de la misma del resto, ubicados en la periferia, con condiciones de empleo y trabajo totalmente diferentes para unos y otros (relativamente buenas en el centro y malas o muy malas en las subcontratadas). Los convenios colectivos validaban estas distancias, dejando explícitamente fuera (de la regulación más favorable) a los trabajadores de las tercerizadas.

\footnotetext{
${ }^{14}$ Para facilitar el alcance de estas nuevas competencias, las técnicas del Management moderno incorporaron, como requisitos exigidos para la contratación o promoción de los trabajadores, la predisposición a dar respuestas rápidas a los desafíos y a proponer soluciones o nuevos proyectos ante necesidades de las empresas, requisito al que denominaron como "proactividad".
} 
Otro factor correlativo, en algunos casos, con la tercerización fue el desarrollo de nuevas actividades ligadas a los cambios productivos en las firmas. El impulso de las respuestas rápidas a las necesidades de los clientes y a la diversificación de las entregas de los productos terminados hizo que comenzaran a proliferar empresas de call centers y de logística, que funcionaron, en gran parte de los casos, como subcontratistas de las grandes firmas.

Una serie de factores se concatenaron para incrementar el tiempo de trabajo de parte de los sectores medios de la población. Las sucesivas crisis hicieron necesaria la multiplicación de fuentes de ingreso, impulsando el pluriempleo; en forma simultánea el management moderno impuso un fuerte involucramiento de los cuadros medios con las necesidades de las empresas y, con ello, la prolongación de sus jornadas de trabajo; complementariamente a alguno de estos factores debe adicionarse la salida masiva de las mujeres al mercado de trabajo. Conjunto de factores que indujo la aparición, entre otros, de nuevos servicios de asistencia a las necesidades domésticas, como los negocios de comidas rápidas y los deliverys.

En definitiva, el trabajo cambiaba y con él emergían también nuevas actividades y, con ellas, nuevos trabajadores, cuyas características iban a contrastar con las que hasta entonces eran representadas por los sindicatos.

Estas condiciones hicieron emerger un proceso en el cual los contrastes identitarios entre las dirigencias sindicales tradicionales y los nuevos trabajadores se hacían cada vez más notorios. Esto comenzó a manifestarse en la aparición de nuevas organizaciones que trataban de representar a trabajadores que no podían o no se sentían incluidos dentro de las actividades ya representadas por los sindicatos existentes. Los sindicatos tradicionales comenzaron a resistir esta posibilidad, originándose disputas por la representación en diferentes ámbitos. Partiendo del hecho que "la lógica sistémica de la LAS adopta como tipo preferencial y excluyente el formato de agremiación en organizaciones por rama de actividad (Tribuzio, 2012: 20)", las organizaciones que contaban con la representación en ellas se sintieron con el derecho a protegerlas y hasta a ampliarlas, incorporando forzadamente actividades que poco tenían que ver con la definición originaria de dichas ramas.

Como ejemplo de esta nueva realidad, en agosto de 2004, más de 2000 trabajadores pertenecientes a la empresa de telemarketing Atento, controlada en un vol.08, nº. 01, Rio de Janeiro, 2015. pp. 386-419 398 
40\% por Telefónica de Argentina, iniciaron el reclamo por mejores condiciones salariales y de trabajo, solicitando además pasar al CCT de la Federación de Obreros y Empleados Telefónicos de la República Argentina (FOETRA), pretendiendo abandonar así el sindicato que los representaba hasta entonces, la Federación Argentina de Empleados de Comercio y Servicios (FAECyS $)^{15}$. Se iniciaba entonces un tipo novedoso de conflicto, no sólo entre un sindicato y la empresa empleadora sino que ahora se le adicionaba un conflicto intersindical. La similitud de tareas realizadas por los teleoperadores de Atento y las que realizaban los trabajadores de las telefónicas motivó el apoyo de FOETRA a esta protesta. El desenlace final de la disputa por el encuadramiento entre los dos sindicatos fue resuelto a favor de la FAECyS, pero, tal como lo indica Abal Medina (2010), este proceso de lucha constituyó un aprendizaje de importancia para los trabajadores que, dentro de la misma actividad, en adelante iban a encarar nuevas formas de organización y resistencia frente a los empleadores. Los trabajadores ahora sabían que no podían quedar expuestos ante el empleador y tampoco podían esperar la solidaridad o el apoyo de los sindicatos existentes ${ }^{16}$, ante lo cual sus nuevos espacios de organización comenzaron a darse por fuera de la institucionalidad y desenvolviendo estrategias de protesta y resistencia asentadas en prácticas realizadas en forma "clandestina".

Otro caso, alguna de cuyas características pueden asimilarse al anterior, fue el protagonizado por trabajadores del supermercado Wal Mart de Avellaneda. Allí, hacia mediados de los años 2000 un grupo de jóvenes trabajadores comenzó a articular fuerzas y conocimiento para presentarse como alternativa de representación sindical en el supermercado, logrando espacios en la comisión interna (CI) del mismo y planteando una forma de representación diferente a las que tradicionalmente desenvolvían quienes se alineaban en el gremio con representación en dicho local, el Sindicato de Empleados de Comercio de Lanús y Avellaneda (SECLA) ${ }^{17}$. Se desarrolló entonces, una experiencia inédita en esta empresa, cuyas prácticas antisindicales eran comunes a cada una de las

\footnotetext{
${ }^{15}$ El CCT de FOETRA garantizaba a los trabajadores la mejoría salarial y otras protecciones sindicales que la FAECyS no les ofrecía.

${ }^{16}$ En el conflicto de Atento, el retiro final de la escena por parte de FOETRA dejó a quienes habían encarado la lucha sin ninguna protección, expuestos ante el empleador y la FAECyS (Abal Medina, 2011)

${ }^{17}$ Sindicato adherido a la Federación Argentina de Empleados de Comercio y Afines (FAECyS). vol.08, $n^{\circ}$. 01, Rio de Janeiro, 2015. pp. 386-419 
sucursales localizadas en distintos países. De una representación asentada solamente en la gestión individualizada de las reivindicaciones se pasó a una práctica sindical que "remite a la idea de trabajador como sujeto colectivo" (Abal Medina, 2011: 55). La experiencia fue propagándose a otros locales de la misma empresa y hasta supermercados de otras cadenas. Durante todo el período en que este grupo de trabajadores ejerció la representación de sus compañeros, sostuvo lo que Abal Medina (2010) denomina como "doble confrontación", contra la empresa pero también contra el propio sindicato, que incluso puede aliarse con la primera para neutralizar el accionar disruptivo con su propia lógica de funcionamiento. Finalmente, luego de sufrir discriminaciones y despidos, algunos de los jóvenes ex delegados se nuclearon definitivamente en la CTA y conformaron un espacio dentro de la Federación de Trabajadores de la Industria y Afines (FETIA), desde donde tratan de organizar a trabajadores de distintos comercios de todo el país y transmitir la experiencia adquirida a partir de la práctica que desarrollaron ellos mismos en Wal Mart.

Un caso emblemático de generación de una nueva organización sindical es el de los trabajadores del Subterráneo de la Ciudad de Buenos Aires ${ }^{18}$. La privatización de este servicio público trajo aparejada una profunda modificación en la gestión de la fuerza de trabajo, asentada fundamentalmente en la flexibilización laboral y complementada con una importante renovación del plantel de trabajadores. Las prioridades de Metrovías (la concesionaria del Subte, desde la privatización del servicio realizada por el gobierno de C. Menem, en 1994) para las nuevas contrataciones de personal se dirigían a contar con trabajadores que tuvieran poca experiencia laboral anterior y ninguna inclinación política. Pero, al parecer, esta última prevención no fue llevada a cabo de manera totalmente eficiente por los encargados del proceso de reclutamiento, dado que algunos de los jóvenes contratados traían ya alguna militancia política previa en partidos de la izquierda trotskista. Ellos fueron quienes nutrieron, en un primer momento, las filas de las primeras e incipientes formas organizativas desarrolladas al interior del Subte, cuyas prácticas se llevaban a cabo en forma clandestina. Opción que tomaban no sólo para eludir las posibles represalias de la empresa sino también para evitar las que pudiera imponerles la Unión Tranviarios Automotor (UTA), sindicato que cuenta con la

\footnotetext{
${ }^{18}$ Para un detalle mayor de este proceso ver Ventrici (2012).
} 
representación institucional de ese ámbito y que no estaba dispuesto a compartirla con otra organización. Desde febrero de 1997 hasta el 2000 una serie de conflictos impulsaron una participación más activa de parte de quienes componían estas organizaciones y, a su vez, la conformación de espacios propios que legitimaran sus posiciones diferenciales respecto del gremio. En septiembre de 2000, los nuevos representantes pasaban a ser mayoría en el Cuerpo de Delegados (CD), posición que fueron revalidando y aumentando en posteriores elecciones. Desde entonces, la resolución de varios conflictos con la empresa (cambios en la estructura con traslado de trabajadores a otros puestos, despido de trabajadores, recuperación de las seis horas de trabajo y eliminación de las tercerizaciones) hizo que el CD adquiera fuerte legitimidad entre los trabajadores del Subte, prácticamente relegando a la UTA a un papel meramente institucional (la negociación y firma del convenio colectivo ${ }^{19}$ ). Luego de intentar en vano (por las dificultades que imponía la UTA) la disputa de espacios al interior del sindicato, en febrero de 2009, tras una consulta con todos los trabajadores y después de sortear diferencias en el CD, los delegados decidieron crear una organización propia, la Asociación Gremial de Trabajadores de Subte y Premetro (AGTSyP), cuya personería jurídica recién le fue otorgada el 25 de noviembre de 2010, y se encuentra aún pendiente de otorgamiento la personería gremial ${ }^{20}$.

En septiembre de 2005 se eligieron representantes para la CI en la planta de Kraft-Terrabusi, en la ciudad de Pacheco de la Provincia de Buenos Aires. En dicha elección se incorporaron nuevos delegados, todos ellos jóvenes, en su mayor parte de militancia trotskista, que habían sido contratados por la empresa después de 2002. Esta representación contrastaba fuertemente con la que promovía hasta entonces el gremio con personería gremial en la rama, el Sindicato de Trabajadores de la Industria de la Alimentación (STIA). En mayo de 2008 este mismo grupo de trabajadores logra ganar las elecciones para el Cuerpo de Delegados, desde donde otorgaron su propia lógica a la representación de los trabajadores (Varela y Lotito, 2012). En 2009 ese CD protagonizó

\footnotetext{
${ }^{19}$ Prerrogativa que tiene por ser el sindicato con personería gremial.

${ }^{20}$ Como ocurre en otros casos, la personería gremial, correspondiente al sindicato de rama (UTA), se extiende a todo el transporte de pasajeros del país. Entonces, a pesar de contar con la mayoría de los afiliados en el Subterráneo de la Ciudad de Buenos Aires, según lo que indica la LAS, para obtener la personería gremial la AGTSyP debería alcanzar la mayor representatividad en toda la rama, tarea que resulta de imposible concreción, ya que esta última organización sólo pretende representar a una parte de ellos, los trabajadores del Subterráneo.
} 
un largo conflicto, en medio del cual la empresa despidió 158 trabajadores y pidió el desafuero de los delegados. La respuesta de la CD fue la toma de fábrica, que se prolonga entre el 9 y el 25 de septiembre, momento cuando el Juez de Garantías de San Isidro ordena el desalojo de la planta. Cuando se restablecen las operaciones en la empresa, se firma un Acta de Acuerdo entre la empresa, los Ministerios de Trabajo Nacional y Provincial, el STIA y tres de los cinco delegados de la CI, en la cual la empresa se comprometió a reincorporar a 40 de los despedidos (ya se había reincorporado a otros 30), a la revisión individual de la situación del resto de los despedidos y los representantes gremiales se comprometieron no entorpecer la producción (Campos y Lira, 2011).

Más allá de las resoluciones de cada caso en particular y de la valoración que se pueda hacer sobre cada experiencia, lo importante a destacar es que en todos ellas se pusieron en contradicción las lógicas tradicionales de ejercer la representación, al mismo tiempo que los nuevos delegados u organizaciones obreras alcanzaron niveles de legitimidad en los lugares de trabajo que eran imposibles de ser alcanzados por los sindicatos que, en dichos ámbitos, contaban con la representación institucional. En función de dicha legitimidad, algunas de estas organizaciones lograron ser reconocidas e incorporadas por sus respectivos empleadores y, en ciertos momentos, por el propio Estado, en las negociaciones, lo cual suma otro dato de importancia acerca de la invalidez de la ley vigente, ya que en ninguno de los casos se trataba de organizaciones con personería gremial.

\section{Los fallos de la Corte Suprema}

En los últimos años, la CSJN parece haber reconocido que la LAS ya no refleja de manera cierta la realidad vigente. Cuatro fallos, en casos de distintas características, cuestionan sendos artículos de dicha Ley.

El primero de dichos fallos se produjo en noviembre de 2008, en un juicio entre la ATE, gremio perteneciente a la CTA, y el sindicato del Personal Civil de las Fuerzas Armadas (PECIFA), en el que se determinó que los trabajadores del primer gremio 
puedan disputar la representación sindical sin necesidad de estar afiliados a PECIFA, declarando de esta forma la inconstitucionalidad del artículo 41 de la Ley $23 \cdot 51^{21}$.

En diciembre de 2009, un nuevo fallo de la Corte declaró inconstitucional al artículo 52 de la misma ley, por el cual sólo se reconoce la tutela gremial a los delegados de un sindicato con personería gremial (PECIFA). El fallo amplió el reconocimiento de tutela a la presidenta del gremio Asociación de Profesionales de la Salud del Hospital Naval (PROSANA), quien trabajaba en un hospital de la Armada y había sido suspendida por sus autoridades.

El 7 de diciembre de 2012, la Corte determinó la reincorporación de un trabajador de la empresa Cencosud, que había sido despedido junto a otros cuatro compañeros, quienes habían conformado una organización sindical para representar los intereses de los empleados jerárquicos de dicha empresa, el Sindicato de Empleados Jerárquicos de Comercio, después que el Sindicato de Empleados de Comercio (SEC), entidad que tiene la personería gremial en el sector, les había negado la afiliación. En este fallo, la CSJN recurre a la Ley № 23.592, aplicándola también al empleo privado y disponiendo que el despido corresponde a un hecho de discriminación sindical. De esta forma, vuelve a ratificarse que los representantes sindicales pertenecientes a organizaciones sin personería gremial también cuentan con la protección tutelar y no pueden ser despedidos de forma discriminatoria.

Finalmente, el 18 de junio de 2013, en el caso planteado por ATE frente a una reducción de salarios realizada por la Municipalidad de Salta, aduciendo una situación de emergencia general, la CSJN declara inconstitucional el art. 31 inc. A. ${ }^{22}$ de la LAS "en la medida que los privilegios que en esta materia otorga a las asociaciones con personería gremial, en desmedro de las simplemente inscriptas, exceden el margen autorizado por las primeras" ${ }^{23}$. En su momento, La Corte de Justicia de Salta había rechazado la acción de ATE, aduciendo que esta organización no contaba con legitimidad para representar los intereses colectivos de los trabajadores de ese

\footnotetext{
${ }^{21}$ El inc. A de dicha ley establece que para ser elegido como delegado, un trabajador debe estar afiliado a la respectiva asociación sindical con personería gremial, con representación en el ámbito en que se desempeñe como trabajador, y ser elegido en comicios convocados por dicha asociación.

${ }^{22}$ Este artículo dice que los sindicatos tienen como derecho exclusivo el de "defender y representar ante el Estado y los empleadores los intereses individuales y colectivos de los trabajadores,"

${ }^{23} \mathrm{http}$ ://www.agenciacta.org/spip.php?article8974 (página visitada el 11/4/2014) vol.08, nº. 01, Rio de Janeiro, 2015. pp. 386-419 
municipio porque había actuado como organización sindical simplemente inscripta y ya existía otro sindicato (la Unión de Trabajadores Municipales de Salta), que contaba con personería gremial y, por lo tanto, según el art. 31 de la LAS, era el único con pleno derecho a defender los intereses colectivos de los trabajadores. Este fallo ataca el corazón del modelo sindical, porque iguala los derechos de las organizaciones que sólo cuentan con personería jurídica con las que tienen además la personería gremial.

\section{MODELO SINDICAL EN PERSPECTIVA INTERNACIONAL}

Construir una tipología de modelos sindicales en una perspectiva internacional resulta una tarea compleja derivada de las diferencias de los contextos en los que se desenvuelven los sindicatos, de los factores que moldearon el nacimiento de las propias organizaciones sindicales y de las estrategias emprendidas por los actores sociales para crear una cierta institucionalidad. Incluso el "modelo sindical" resulta ser un modismo al que se apela para referirse a cuestiones sustancialmente variadas. En este sentido, el mismo se suele analizar desde la óptica de la representación sindical en los lugares de trabajo, de la definición de la representación en la negociación colectiva, de la existencia y de la intensidad de las normas que definen al sindicato más representativo, de los mecanismos que determinan la elección de las autoridades, entre otros puntos de vista.

Evidentemente, todos los factores que confluyen en lo que se denomina modelo sindical, se traducen en definitiva en una mayor o menor capacidad de las entidades sindicales de intervenir en el diseño de las políticas que afectan la calidad de vida de los trabajadores. La proporción de trabajadores afiliados a los sindicatos, la proporción de trabajadores comprendidos en la negociación colectiva, el número de delegados presentes en los lugares de trabajo, son indicios relativos de esta capacidad de los sindicatos de influir realmente en las condiciones laborales de la población.

En este apartado ahondaremos en la dimensión de la representación de los trabajadores en la empresa, pretendiendo rescatarla desde la perspectiva internacional, la cual resulta seguramente incompleta a la luz de la inmensidad de experiencias de las que se derivan los modelos nacionales. El eje del relevamiento comparado estará puesto en el desarrollo de los modelos nacionales en algunos países centrales de Europa y en 
otros países de América del Sur, de los que se intentará suministrar características comunes y diferenciales, a los fines de contrastarlos con la experiencia argentina.

Esta dimensión estará enfocada a brindar un panorama respecto de la situación de la representación de los trabajadores en las empresas y los centros de trabajo, enfatizando la distinción de los mecanismos de elección de estos representantes y las relaciones que se establecen con las organizaciones sindicales.

\section{Representación de los trabajadores en la empresa}

Con respecto a la representación de los trabajadores en los lugares de trabajo, emergen claras diferencias entre lo que acontece en los dos continentes, que dejan como saldo un atraso relativo en el desarrollo de esta institucionalidad en los países de América del Sur, algunas de cuyas características detallamos a continuación:

1. En Europa existe una importante tradición, que no se registra en todos los casos latinoamericanos, de elección directa de los delegados en los establecimientos;

2. Los escenarios de organizaciones sindicales más débiles, combinados con una importante extensión de la informalidad laboral, atentan contra las posibilidades de agremiación en las empresas instaladas en América Latina;

3. El ingreso de capitales extranjeros en contextos de globalización y de apertura, en especial durante los noventa, abrió la puerta al avance empresario en las estrategias de descentralización productiva y de tercerización, que debilitaron la posición de los trabajadores y desestimularon su capacidad de organización colectiva;

4. La impronta dejada por un pasado de dictaduras militares diezmó las organizaciones sindicales y debilitó las reales capacidades de organización de los trabajadores en el seno de las empresas;

5. El menor peso de la industria manufacturera en la estructura productiva, repercute en forma negativa en las estrategias sindicales de agremiación y de representación de los trabajadores. Por tanto, se requiere necesariamente de nuevas respuestas del movimiento obrero para dar cuenta de las demandas, en particular, en sectores poco propicios para la acción sindical como en los servicios y en la actividad agrícola; 
6. La ausencia, fragilidad o debilidad de los mecanismos de tutela sindical entre los trabajadores electos como delegados gremiales o los que se presentan a elecciones sindicales actúa como disuasivo para desalentar la presencia de representantes.

La representación de los trabajadores está siendo sometida a tensiones diversas, que están provocando modificaciones en los factores estructurantes que moldearon las características esenciales de los modelos nacionales de relaciones laborales. En este sentido, el acuerdo que consagró la unidad monetaria europea restó recursos a los gobiernos nacionales para implementar políticas contracíclicas de corte keynesiano. En el campo político están apareciendo tensiones en la forma de una confrontación entre quienes demandan una profundización de las prácticas flexibilizadoras de las condiciones de trabajo y las organizaciones sindicales, que buscan resistir a las presiones de debilitamiento sindical para impedir el avance flexibilizador, pero que se hace cuesta arriba por la magnitud y la persistencia del desempleo (como en el caso de España).

Distinta es la coyuntura más inmediata de América Latina, que con distintos matices, intensidad y características de los respectivos proyectos políticos y económicos está logrando una mejora significativa de las condiciones de vida de los grupos más vulnerables de la población, situación a la que está contribuyendo sin duda, el quiebre de orientación neoliberal de las políticas sociales. En este contexto, el movimiento obrero latinoamericano recupera las condiciones objetivas para recomponer sus fuerzas, a causa del crecimiento económico experimentado, del abandono de las políticas neoliberales, y porque los nuevos proyectos impulsados se asientan en la apertura a la participación de las organizaciones sindicales.

A continuación señalaremos los rasgos centrales de los mecanismos nacionales de representación de los trabajadores en los centros de trabajo, de los países objeto de estudio.

En Brasil, si bien el derecho de los trabajadores a elegir sus representantes está contemplado en la Constitución Federal (CF), este derecho no fue reglamentado, y en la práctica resulta inaplicable (Campos et al, 2011). En la CF se establece que en las empresas de más de 200 trabajadores se podrá elegir representantes de personal con el propósito exclusivo de "promover el entendimiento directo con los empleadores". Por 
otra parte, la legislación no estipula ninguna protección "especial” contra el despido arbitrario o las posibles prácticas antisindicales emprendidas por empresarios. Los avances que se concretaron en materia de representación de los trabajadores en las empresas se lograron mediante el canal de la negociación colectiva. Finalmente, la legislación brasilera admite la creación de una Comisión Interna de Prevención de Accidentes (CIPA) de carácter mixto, con el objeto de prevenir accidentes y mejorar el medio ambiente de trabajo.

En Chile ${ }^{24}$, la legislación promueve la fragmentación de la representación y la conformación de sindicatos de empresa, y desalienta toda forma de representación sectorial o por rama de actividad (Doniez, 2012). En las empresas de más de 50 trabajadores se requiere un mínimo de 25 trabajadores (equivalentes a más del $10 \%$ de la dotación) para constituir un sindicato. Asimismo, se admite la conformación de "grupos negociadores" no sindicales compuestos de un mínimo de sólo 8 trabajadores, que pueden asumir funciones de negociación colectiva, aunque en el mismo ámbito exista representación sindical ${ }^{25}$. Finalmente, la presencia de "grupos negociadores" es más habitual en las grandes empresas, mucho más aún en aquellas que cuentan con representación sindical, fenómeno que puede leerse como una estrategia empresaria orientada a fragmentar la representación de los trabajadores y debilitar su capacidad de organización colectiva ${ }^{26}$.

En Europa central (Alemania, Francia y España), se observa un claro predominio del modelo "dual" de representación en la empresa. Esto implica que en la empresa convive un esquema de representación unitaria (no sindical) con otro esquema de representación sindical. El doble canal de representación combina la representación de base electiva, que requiere necesariamente del voto de toda la dotación para elegir a sus representantes, con aquella de base asociativa, que se determina en base a la afiliación efectiva al sindicato. El procedimiento para la elección de representantes, en lo que

\footnotetext{
${ }^{24}$ Chile presenta una de las tasas más altas de asalarización con una reducida proporción de empleo no registrado y, como contrapartida, registra los niveles más bajos de sindicalización.

${ }^{25}$ También se admite la negociación con grupos de trabajadores no conformados como sindicatos en Colombia, Perú y Paraguay.

${ }^{26}$ Los últimos datos disponibles de la Encuesta Laboral (ENCLA) de 2011 revelaba que sólo el 7,8\% de las empresas de 5 y más ocupados tenía un sindicato activo, con muy baja incidencia en las pequeñas empresas. En las empresas pequeñas y medianas es recurrente la representación a través de un solo sindicato, pero en las grandes empresas alcanza dimensiones importantes la presencia de tres o más sindicatos.
} 
hace a las especificidades con respecto a cantidad de representantes electos y la relación entre ambas formas de representación es lo que forja las diferencias entre las experiencias nacionales.

En Alemania, el sistema de representación de los trabajadores en la empresa se compone de dos instancias representativas (Dribbusch y Birke, 2012). El primero es el consejo de fábrica (o comité de empresa), que funciona como sistema unitario de representación, con funciones de co-determinación en cuestiones individuales y colectivas. Se integra con representantes elegidos por el voto de todos los trabajadores de la empresa y no requiere para la postulación estar afiliado al sindicato. El número de integrantes del consejo de fábrica depende del tamaño de la empresa, pero recién cuando se supera los 200 empleados, un delegado electo recibe el derecho de estar licenciado totalmente de su trabajo. La segunda forma de representación, la constituye la cogestión en los órganos de administración de la empresa, que está admitida exclusivamente en las empresas constituidas como sociedades anónimas de tamaño grande, con más de dos mil trabajadores. La regulación del funcionamiento de la cogestión establece que se debe instaurar una representación igualitaria entre los representantes empresarios y de los trabajadores en los órganos directivos de las empresas.

En el modelo francés de representación en la empresa conviven tres órganos de representación de los trabajadores que asumen funciones disimiles y complementarias entre sí: comité de empresa, delegado de personal y seccional o delegado sindical (Molinero, 2010). Los dos primeros son órganos unitarios y electivos, mientras que el delegado sindical es el órgano asociativo, que asimismo, tiene asignada la función (en el caso del o de los sindicatos representativos) de negociar colectivamente con los empleadores $^{27}$.

\footnotetext{
${ }^{27}$ Cada representación sindical estará conformada por no más de dos delegados y, en el caso, que esta delegación no se pueda completar con delegados puede hacerse con asalariados de la empresa. Cuando no haya delegados sindicales están habilitados los representantes elegidos por los trabajadores para el Comité de Empresa (delegados de personal) o uno o varios trabajadores con mandato de sus compañeros, para concluir convenios de empresa. Otra excepción es la negociación de condiciones de implementación del sistema de participación en los beneficios que pueden ser pactados por sindicatos o por los comités de empresa.
} 
Sólo los sindicatos representativos ${ }^{28}$ pueden designar un delegado sindical sobre la base de la afiliación de los trabajadores de la empresa. A su vez, los delegados designados representan a estos sindicatos, que asumen está condición de representatividad por la condición de afiliación a la confederación representativa. Es decir, los sindicatos afiliados a una confederación representativa se convierten automáticamente en representativos "por irradiación" en la empresa. Además se establece un umbral mínimo de 50 trabajadores para que los sindicatos puedan nombrar a sus representantes en la empresa. En las empresas de menos de 50 trabajadores se puede designar un delegado sindical a condición que reúna simultáneamente la función de ser delegado de personal.

El "comité de empresa" es un órgano mixto de creación obligatoria en empresas de 50 y más ocupados, que cumple funciones de información y de consulta, creado con la finalidad de instituir el diálogo entre capital y trabajo. La convocatoria a elecciones de integrantes del comité de empresa es una obligación que recae en el empleador, y su incumplimiento está catalogado de delito contra la libertad sindical. La representación se conforma por representantes de los empleadores y de los trabajadores (que integra el criterio electivo y asociativo). El número de delegados de personal variará en función del tamaño del establecimiento, asignando entre 1 y 9 delegados cuando el establecimiento tuviera menos de 1000 dependientes, agregándole un delegado más cada 250 trabajadores. Las atribuciones que tiene asignadas el delegado de personal son el control y aplicación de la normativa laboral de parte del empleador, actuar de intermediario frente al empleador en caso de reclamos individuales y colectivos de los trabajadores. Cuando la empresa no logre conformar un comité de empresa, el delegado

\footnotetext{
${ }^{28}$ A partir de la Ley del 20 de agosto de 2008 , que se puso en vigor en 2013 , un sindicato es representativo en el ordenamiento jurídico francés cuando cumpla con los siguientes criterios: i) respeto por los valores republicanos; ii) independencia; iii) transparencia financiera; iv) antigüedad mínimo del sindicato de dos años; v) la audiencia electoral; vi) la antigüedad y la experiencia; vii) el volumen de afiliados y cotizaciones. El dato crucial de esta ley es la medición de la audiencia electoral, que remite a las elecciones de delegados que se realizan, cada cuatro años, a nivel de las empresas y establecimientos. Para ser representativo en la empresa un sindicato debe obtener al menos el 10\% de los votos de los trabajadores. Para ser representativo a nivel de rama, los sindicatos deben obtener al menos el 8\% en dicho ámbito. En las elecciones realizadas en 2013, los resultados fueron variados en cada rama, pero la representatividad, a nivel de confederaciones, recayó fundamentalmente en las cinco centrales sindicales que ya habían sido designadas como representativas (CGT; CFDT; CGT-FO; CFTC y CFE-CGC).
} 
suplantará las funciones que ese órgano debe cumplir para la defensa de los intereses de los trabajadores.

El modelo de representación español también es de carácter dual, como en el caso alemán y francés, permitiendo la representación unitaria y sindical en una misma empresa. El régimen unitario se expresa a través de la elección de delegados de personal y/o comité de empresa por parte de todos los trabajadores. Los delegados de personal existen en empresas que cuentan con una dotación comprendida entre 10 y 50 trabajadores. En las empresas o centros de trabajo con dotaciones entre 6 y 29 trabajadores, tendrán derecho a elegir un delegado de personal, y en empresas entre 30 y 49 dependientes, podrán designar tres delegados. En los establecimientos de más de 50 trabajadores la representación asume la forma de comité de empresa, transformando al conjunto electo de delegados en un órgano representativo del personal (Tovar, Baylos y Trillo, 2013).

La representación sindical en las empresas se compone de los delegados sindicales y de secciones sindicales, ambas expresan la representación sindical de los trabajadores en dicho ámbito. El esquema asociativo, que coexiste con la representación unitaria, requiere para su conformación la afiliación de los trabajadores a los sindicatos respectivos, porque éstos a través del voto eligen a los representantes sindicales en los centros de trabajo. La constitución de una seccional sindical es un derecho atribuido a los trabajadores afiliados a un sindicato. En este sentido, en la empresa cohabitarán tantas seccionales sindicales como opciones de sindicalización se hayan expresadas por los trabajadores. Además, las seccionales sindicales de los sindicatos más representativos (principio de irradiación) o de las que tengan presencia en los esquemas de representación unitaria en la firma asumirán funciones adicionales. La representatividad se determinará en función de los resultados obtenidos en las audiencias electorales, es decir, que los sindicatos que obtengan la mayor cantidad de delegados en los órganos de representación unitaria en la empresa serán los más representativos. Se impulsa de este modo un potente mecanismo de integración entre la representación unitaria de base electiva y la representación sindical en la empresa.

\section{UN MODELO PARA CADA CONVENIENCIA}


Tomando el ejemplo de ciertas estructuras sindicales europeas, y forzando quizás la comparación de realidades, historias y culturas completamente diferentes, una de las principales críticas que se le realizan al sindicalismo argentino es la ausencia de pluralismo en su compleja estructura global. Como vimos, algunos de los fallos de la CSJN cuestionan directamente las limitaciones que se generan en este sentido. Sin embargo, según la opinión de $\mathrm{P}$. Wasiejko ${ }^{29}$ la realidad parece desmentir este aserto. Según este dirigente, en muchas actividades conviven varios sindicatos, creados más allá de la existencia de leyes que, en cada momento, regularon la unicidad sindical. Lo que se denomina como "modelo sindical" argentino y es alabado por distintos sindicalistas y analistas ya no existe tal como fue creado y consolidado durante el primer gobierno peronista. Los distintos gobiernos posteriores a 1955, democráticos o dictatoriales, se encargaron de desmembrarlo, utilizando la misma ley para "favorecer a sectores que tenían cierta afinidad o cierta amistad o compromiso político-ideológico para darle un espacio de construcción organizativa dentro del movimiento obrero", generando situaciones como lo que sucede en el puerto de la CABA, donde en "un colectivo que no llega a 15000 trabajadores hay 26 organizaciones sindicales, que representan diferentes actividades, casi al mejor estilo del modelo anarquista, del sindicato por oficio", lo mismo puede suceder en la actividad aeronáutica, donde para aproximadamente 15000 trabajadores hay alrededor de 14 sindicatos.

Siguiendo con esta lógica de pensamiento, Wasiejko dice que el modelo creado en 1945, fue absolutamente tergiversado, ya que si lo que Perón buscaba era que existieran organizaciones con peso propio para negociar con los empresarios lo que existe actualmente es un sistema que lo único que permite es que "las empresas puedan seguir a su antojo decidiendo donde encuadran a los trabajadores, pero los trabajadores no tienen acá ningún derecho". En el tiempo se generó un sistema del cual los empresarios son los mayores beneficiarios, ya que tienen a su disposición organizaciones “débiles, que no molesten en su actividad", las cuales gracias a esta práctica aseguran su financiamiento y supervivencia, a un sistema que tolera y legaliza el Ministerio de Trabajo.

\footnotetext{
29 Secretario General del Sindicato Único de Trabajadores del Neumático (SUTNA) y Secretario Adjunto de la CTA. Las opiniones vertidas en este artículo corresponden a una entrevista realizada, al sindicalista, por los autores el 10/4/2014.
} 
El mismo dirigente afirma que son los trabajadores quienes tienen que "recuperar su capacidad autónoma de decidir como se organizan", porque actualmente (...) "es más fácil hacer un partido político en nuestro país y presentarse a elecciones y tener horas y horas antes de una elección para usar gratis el espacio público de los medios audiovisuales para hacer propaganda..., ahora es casi imposible organizar un sindicato".

A pesar de proponer una apertura del sistema legal que propicie mecanismos que faciliten la creación de nuevas organizaciones de los trabajadores, este sindicalista rechaza una total liberalización del sistema, indicando que: (...)”lo que tiene que haber es una situación intermedia. Es peligroso entrar en un modelo totalmente liberal, en que cada individuo va adonde le parece ¿no? (....) esto puede degenerar en el modelo chileno".

Según L. Piasek ${ }^{30}$ las transformaciones acontecidas en el ámbito de la producción y de la estructura de las organizaciones sindicales alteraron profundamente los rasgos salientes del modelo sindical argentino. En este sentido, sostiene que "no existe modelo sindical tal cual se venía planteando (como se diseño en la Ley de Asociaciones Sindicales), ni para los que lo defienden ni para los que lo cuestionan". Agrega además que el modelo sindical "implosionó" como consecuencia de la tendencia a la erosión de la prevalencia del sindicato de actividad y de la unicidad promocionada ${ }^{31}$. A su entender, son ejemplos de las tendencias señaladas, el crecimiento en el número de sindicatos, no sólo los que fueron reconocidos por la autoridad de aplicación (otorgándoles la personería o la inscripción simple gremial) sino también los que solicitan la inscripción, los conflictos de encuadramiento entre sindicatos y el solapamiento entre diversos sindicatos que aspiran a representar a un mismo colectivo de trabajadores. Con el crecimiento del empleo experimentado en los últimos años emergen colectivos de trabajadores que sólo reconocen la representación de las comisiones internas elegidas en el establecimiento o de organizaciones no formales que actúan de hecho.

El mismo especialista plantea la necesidad de atacar las diferencias entre los sindicatos con personería y aquellos que solo cuentan con inscripción gremial. La forma

\footnotetext{
${ }^{30}$ Abogado, representante legal de varios sindicatos y especialista en la problemática del modelo sindical. Las opiniones vertidas en este artículo corresponden a una entrevista, a L. Piasek, realizada por los autores el 11/4/2014.

${ }^{31}$ Denominación con que comúnmente se caracteriza al modelo sindical encarnado por la LAS vol.08, nº. 01, Rio de Janeiro, 2015. pp. 386-419 
de establecer algún tipo de protección para estos últimos sería: tutelando a los representantes de sindicatos simplemente inscriptos, así como la legislación actual habilita a representantes de sindicatos reconocidos con personería gremial. Un registro especial debería ser el ámbito donde los sindicatos alcancen la inscripción y no el Ministerio de Trabajo.

Piasek indica además que en el esquema vigente observa una importante autonomía de los empleadores para elegir el encuadramiento sindical y convencional de los trabajadores, que gran parte de las veces lo determinan en función de sus propias conveniencias, en atención a los objetivos de lograr maximizar sus ganancias. A este resultado contribuyeron ciertos sindicatos que son subsidiarios de la lógica de la tercerización, que en la práctica "no tenían presencia activa en estos establecimientos y las tareas que hacían los trabajadores no se reflejaban en el convenio....". Entonces, la transformación operada sobre el modelo sindical nace de la falta de representación, pero se profundiza por "el corsé legal que impide cualquier otra forma de organización reconocida legalmente". Ante este obstáculo, en los lugares de trabajo los trabajadores se organizan "pasando por arriba de las organizaciones sindicales", situación que se plasma en los hechos cuando ante un conflicto laboral se acepta que la representación de los trabajadores sea ejercida solamente por los delegados, por organizaciones sin personería gremial o por otras formas de representaciones.

Por su parte, M. Ackerman ${ }^{32}$ rechaza la unidad sindical impuesta ${ }^{33}$, ya que, según su opinión, "cuando el legislador se mete a organizar la vida de los sindicatos hay intereses y esto genera todo tipo de distorsiones.". Posición desde la cual plantea que no es necesaria una ley que imponga dicha unidad. En Argentina, el modelo sindical vigente fue deslegitimado por la práctica, a partir de la cual se dio la aparición de expresiones independientes, que terminan siendo las organizaciones sindicales reales, que el Estado no reconoce. En lo que respecta a la forma que debería tomar la representación sindical, Ackerman sostiene la posición de la OIT, que ve como

\footnotetext{
${ }^{32}$ Mario Ackerman es abogado laboralista, Profesor Titular Regular y Director del Departamento de Derecho del Trabajo y de la Seguridad Social de la Universidad de Buenos Aires. Miembro de la Comisión de Expertos en la Aplicación de Convenios y Recomendaciones de la Organización Internacional del Trabajo. Las opiniones vertidas en este artículo, por M. Ackerman, corresponden a una entrevista realizada por los autores el 29/5/2014.

${ }^{33}$ De esta forma, el especialista caracteriza lo que antes se denominó como "unidad promocionada". vol.08, n. 01, Rio de Janeiro, 2015. pp. 386-419 413
} 
razonable otorgar ciertos privilegios a las organizaciones más representativas (en cuanto a la negociación colectiva o representaciones a nivel internacional, por ejemplo), "pero para todo lo demás debería aceptarse la pluralidad".

Este mismo especialista indica que la proliferación de representaciones sindicales es perjudicial para los empleadores, que ya no pueden dimensionar la cantidad de delegados que pueden tener. De cualquier modo, adjudica parte de la causa de esta disfuncionalidad a la actuación de los mismos empresarios, que "avalaron durante cincuenta años este modelo", por la comodidad de contar siempre con el mismo interlocutor del otro lado de la mesa.

Según Ackerman, es necesario garantizar la tutela, la estabilidad sindical, la protección frente a la discriminación y contra las prácticas desleales, para todos los sindicatos. Entendiendo que un sindicato debe ser aquel que, fundamentalmente, cuente con la capacidad de negociar. Porque, en la actualidad esta capacidad está restringida, en una actividad o empresa donde existe un sindicato con personería gremial, solamente a este último y "un sindicato que no tiene personería gremial no es un sindicato, es otra cosa. El simplemente inscripto no tiene capacidades sindicales. El simplemente inscripto no tiene capacidades sindicales, no tiene legalmente tutela sindical, no tiene derecho a la retención de la cuota, no tiene exención impositiva. Decir que eso también es un sindicato es gracioso. Que la ley lo llame sindicato, pero... lo llama sindicato simplemente inscripto, pero son los kelpers de la vida sindical."

En Argentina, dice Ackerman, "no existe libertad sindical en las categorías conceptuales de la OIT, hay vicios que hacen que no sea la libertad. No hay democracia, esto está claro, pero tampoco hay libertad sindical plena, lo que hay es protección para el ejercicio de derechos sindicales a ciertos trabajadores, esto no es libertad sindical. Los trabajadores no pueden hacer las organizaciones que creen conveniente. Los trabajadores deben darse las organizaciones que mejor les parezca. El gobierno debe promover la unidad, puede establecer un porcentaje mínimo de afiliados, a partir del cual pueda considerarse que un sindicato existe como tal, pero "puede haber tantos sindicatos como quieran los trabajadores y el ámbito lo tienen que decidir los trabajadores." 


\section{CONCLUSIONES}

El modelo sindical argentino, en el "racconto" de su existencia, fue objeto de diversos tipos de cuestionamientos, provenientes tanto desde el interior como del exterior del movimiento obrero. Durante la etapa de proscripción del peronismo (19551973) las divisiones al interior del sindicalismo, a nivel de las cúpulas, no significaron, como elemento central del conflicto, críticas a los rasgos salientes del modelo sindical. Dichas fragmentaciones fueron resultado del posicionamiento político asumido por grupos sindicales con respecto a los gobiernos que ejercieron la administración del Estado y/o debidas a cuestionamientos del gremialismo alternativo a la burocratización de la dirigencia sindical tradicional. Es así que las divisiones dentro del sindicalismo, por controversias respecto a la forma de organización y al ejercicio de la representación, emergen como una característica novedosa del desarrollo histórico reciente.

El avance del neoliberalismo en el país, cuya máxima expresión se apreció con la aplicación de políticas orientadas al libre mercado, durante la década del noventa, dejó enormes secuelas en el plano del empleo y de las condiciones laborales. En esa oportunidad se abrió por primera vez una grieta en el seno del propio sindicalismo, generando una división, que produjo el nacimiento de la CTA. Esta nueva central venía a expresar las contradicciones generadas por la ampliación de la brecha entre la representación formal y la representación real de los trabajadores, producto del aumento del desempleo, el empleo no registrado y el empleo por cuenta propia.

Desde 2003, los incrementos en la producción y en el empleo registrado contribuyeron a la recuperación del funcionamiento de las instituciones laborales, adormecidas durante gran parte del período de apogeo del neoliberalismo, tales como la negociación colectiva (fundamentalmente concentrada en la determinación de salarios) y la convocatoria del "Consejo del salario mínimo, vital y móvil”34. La dinámica de estas instituciones reflejó una mayor actividad de los sindicatos en un contexto de

\footnotetext{
${ }^{34}$ Este Consejo, es un órgano tripartito, en el que participan el gobierno, los representantes sindicales (de CGT y CTA) y los empresarios (a través de sus respectivas cámaras) y está encargado fundamentalmente de establecer, todos los años, el piso mínimo salarial para todas las actividades económicas.
} 
crecimiento económico, incluso también de ciertas organizaciones que, en algunas circunstancias, avalaron las políticas desindustrializadoras, privatizadoras y aperturistas de los noventa. Al mismo tiempo, este nuevo contexto abrió la puerta a nuevas formas organizacionales de los trabajadores que pusieron fuertemente en cuestión las pautas dictadas por la legislación vigente.

Los entrevistados, en la elaboración de este artículo, coincidieron en señalar que este modelo perdió su esencia como consecuencia de la tendencia a la erosión de la unicidad de la representación y la fragmentación del sindicato de rama. Bajo esta realidad, la existencia del criterio de unicidad sindical abre el debate en el campo de las relaciones laborales respecto a si el sindicato que adquiere el monopolio de la representación "representa verdaderamente" los intereses del colectivo de trabajadores en nombre de quien actúa. Estos mismos especialistas afirman que, cuando las nuevas formas de representación no encuentran vías de expresión por los canales institucionales pero, al mismo tiempo, son lo suficientemente representativas y cuentan con el respaldo de los trabajadores, se terminan imponiendo por encima de la estructura legal, e incluso se las reconoce como sujetos autorizados a participar, por ejemplo, de procesos de negociación. Frente a las alternativas que barajan para impulsar una nueva forma de organización de los trabajadores, los entrevistados no se encasillan con la definición de un único modelo predeterminado, estático e inamovible. Consideran que la elección de la manifestación más acertada para representar a un determinado colectivo de trabajadores debe provenir de los mismos trabajadores, y no debería ser impuesta desde arriba sin consenso ni participación democrática. Siempre sigue abierto en ese escenario la posibilidad de un desmembramiento de la representación de los trabajadores en múltiples unidades que se debería atender para no debilitar a la organización sindical.

La perspectiva internacional otorga la posibilidad de extender un abanico de opciones para analizar la representación de los trabajadores, siendo ésta una línea de trabajo que se debería profundizar para aportar nuevas ideas. Se aprecia que en cada uno de los casos analizados de países europeos y latinoamericanos aparecen semejanzas y diferencias con respecto a las distintas figuras que encarnan la representación de los trabajadores en los lugares de trabajo y en la negociación colectiva. Argentina revela ser un caso atípico para América Latina, por la extensión de la negociación colectiva, la tasa 
de afiliación a los sindicatos y la presencia de delegados sindicales en los establecimientos.

En este sentido, la encrucijada que se plantea apunta a determinar el mecanismo para recuperar los aspectos positivos del modelo, pero dirigiéndose a cerrar la brecha abierta entre la representación formal y real de los trabajadores.

\title{
UNION REPRESENTATION IN ARGENTINA: AN ODD CASE
}

\begin{abstract}
Economic, political and cultural transformations generated by neoliberalism in the last decade of the twentieth century, in Argentina, produced a marked weakening of union structures. Beset by unemployment, job insecurity, and new work cultures and discrediting much of its leadership, many of these organizations ended up being functional for the same model. After the abandonment of neoliberal policies and the impetus given by the government of Néstor Kirchner, the unions recovered much of its force. However, the challenges for the trade union model have emerged with more weight than in other historical moments. New workers, some of them engaged in the nineties, formed organizations vying for traditional union representation. At the same time, successive failures of the Supreme Court of Justice of the Nation threatened several articles of the trade unions law; claims of ILO talk about the lack of freedom of association, once that such rules restrict the institutionalization of new unions. This article analyzes this Argentine context, with the most relevant cases that challenge the union system and use comparison and evaluation of several experts in the international area.
\end{abstract}

Keywords: unions, representation, representative, new employees, new organizations.

\section{BIBLIOGRAFÍA}

ABAL Medina, Paula y Crivelli, Karina. Resistencia sindical en el lugar imposible. Los delegados de Walt Mart Avellaneda, en: Colectivos resistentes. Procesos de politización de trabajadores en la Argentina reciente. Comps. Abal Medina, Paula y Diana Menéndez, Nicolás, Buenos Aires: Ed. Imago Mundi, 2011, p. 19-74.

ABAL Medina, Paula . Modos de politización de organizaciones de trabajadores de grandes empresas. Revista Estudios Sociológicos, El Colegio de México, № 82, p. 41-65, enero-abril 2010. 
BATTISTINI, Osvaldo. El modelo sindical en crisis. En, G. Todo aquel fulgor. La política argentina después del neoliberalismo. Editores: Perez, Germán, Aelo, Oscar y Salerno, Gustavo, Buenos Aires: Ed. Nueva Trilce, 2011, p. 119-130.

CAMPOS, Julia. et. al: Representación de los trabajadores en los lugares de Trabajo. Un estudio comparado: Argentina, Brasil, España e Italia. 10o Congreso Nacional de Estudios del Trabajo. Buenos Aires, 2011.

CAMPOS, María Fernanda y Lira, Lucía Genoveva. Organización sindical en el lugar de trabajo, derecho de huelga y aplicación actual de la normativa en Argentina: el caso Kraft Foods. IV Seminario Internacional Políticas de la Memoria: "Ampliación del campo de los derechos humanos. Memoria y perspectivas", Buenos Aires: 29 de septiembre al 1 de octubre de 2011.

DEL CAMPO, Hugo. Sindicalismo y peronismo. Los comienzos de un vínculo perdurable. Buenos Aires: CLACSO, 1983.

DONIEZ, Valentina. El modelo laboral chileno: la deuda pendiente. Claves de políticas públicas № 13, Documento de Trabajo - Universidad Diego Portales, Santiago de Chile, 2012

DRIBBUSCH, Heiner y Birke, Peter. Los Sindicatos en la República Federal de Alemania. Estudio: Fredrich Ebert Stiftung, 2012.

Etala, Carlos. Libertad Sindical y Negociación Colectiva. Aportes para un debate doctrinal. XIX Congreso Nacional de Derecho del Trabajo, Buenos Aires: 10 al 12 de mayo de 2012.

ETALA, Carlos (1995). Las formas institucionales: las grandes líneas de la evolución del derecho colectivo e individual desde la Segunda Guerra Mundial hasta 1992. Buenos Aires: Cuadernos del PIETTE, Serie Relaciones de Trabajo, 1988.

FERNÁNDEZ, Arturo. Crisis y decadencia del sindicalismo argentino. Sus causas sociales y políticas. Buenos Aires: Editores de América Latina. 1998.

GARCÍA, Héctor. Actualidad sobre la representación sindical en Argentina. XVI Jornadas Rioplatenses de Derecho del Trabajo y de la Seguridad Social, Colonia (Uruguay), Organizadas por la Asociación Uruguaya de Derecho del Trabajo y de la Seguridad Social, 25 y 26 de abril de 2009.

GODIO Julio. El movimiento obrero argentino (1943-1955). Hegemonía nacional laboralista, Buenos Aires: Legasa, 1990.

JAMES, Daniel. Resistencia e Integración. El peronismo y la clase trabajadora argentina 1946-1976. 2ª ed. Buenos Aires: Ed. Sudamericana, 1999.

YSÀS Molinero, Helena. La participación de los sindicatos en funciones normativas en Francia. Madrid, Estudios de la Fundación 1o de Mayo / Centro sindical de estudios / CCOO, 2010. 
TRIBUZIO, José Edgard. ¿Un nuevo modelo sindical argentino? Revista Derecho del Trabajo, Buenos Aires, Año LXXII, № 9, p. 2288-2313, septiembre 2012.

TOPET, Pablo. Modelos de libertad sindical en el Río de la Plata. XVI Jornadas Rioplatenses de Derecho del Trabajo y de la Seguridad Social, Colonia (Uruguay), Organizadas por la Asociación Uruguaya de Derecho del Trabajo y de la Seguridad Social, 25 y 26 de abril de 2009 .

TOVAR, Joaquín Aparicio, Baylos, Antonio y Trillo, Francisco. Modelos nacionales de negociación colectiva en Europa. En: Estrategias sindicales por una mayor y mejor negociación colectiva en América Latina y el Caribe. CSA-CSI. San Pablo, 2013, p. 106-170.

VARELA, Paula y Lotito, Diego. La lucha de Kraft-Terrabusi. "Comisiones Internas, izquierda clasista y "vacancia" de representación sindical. Revista Conflicto Social, Buenos Aires, Año 2, № 2, p.256-291, diciembre 2009.

VENTRICI, Patricia. Terroristas. Historia del Cuerpo de delegados del subterráneo. En Metrodelegados. Subte: de la privatización al traspaso. Org. Ventrici, Patricia; Vocos, Federico y Compañez, Manuel. Buenos Aires: Ed. Desde el Subte, 2012, p. 13-124.

Trabalho enviado em 17 de novembro de 2014 .

Aceito em 11 de fevereiro de 2015. 